\title{
Supplier Selection Modeling and Analysis Based on Polychromatic Sets
}

\author{
Binbin Yang, Yongming Wu and Mingqiang Yin \\ School of Mechanical and Electronic Engineering, Guangdong University of Technology, \\ Guangzhou 510006, Guangdong, P.R. China yangbin2590@163.com
}

\begin{abstract}
The competition in 21 century is no longer located among enterprises, but in all the supply chains. To maximize the supply chain benefit, the stable and efficient supply chain should be provided. This paper applies the polychromatic sets to discuss the supplier selection problem and describe the supplier selection related factors. According to those factors, a model is illustrated in detail by means of sets and graphic in the polychromatic sets. The model uses adjacent matrix and contour to modify supplier selection factors. A procedure of selecting suppliers is presented to identify and find competitive suppliers. Then the model is optimized by using genetic algorithm. At the end, a case is provided to show that the methods are effective to select suppliers.
\end{abstract}

Keywords: Supplier selection, Polychromatic sets, Genetic algorithm

\section{INTRODUCTION}

With the development of information technology, an enterprise needs to evaluate and select its suppliers carefully. The supplier evaluation model becomes one of the important research areas in supply chain management (SCM). Generally, the effort to evaluate a supplier is focused on the purchase price, delivery time, product quality, etc. In the supplier selection process, a manager has to consider multi-criteria factors related. Thus the integration of all the multi-criteria analysis and results by multianalysis model has an important meaning in the problem of supplier selection.

\subsection{Known Results}

Several methods for supporting the supplier selection process have been proposed. Chaudhry provided a vivid literature survey, on the application of several programming techniques to supplier selection problem. Narasimh proposed the use of the analytic hierarchy process (AHP) to deal with imprecision in supplier choice. Shiromam used genetic algorithms together with a fuzzy satisfied method to solve complex conditions and criteria in a multi-supplier supply chain environment. Dulmin and Mininno used multi-criteria decision analysis method in supplier selection problem, and Hwang used a product-driven method for supply chain selection. 


\subsection{Our Aims}

A good supplier selection process must take into account all factors that affect supply chain performance and the selection must be done to increase supply chain profits in a way that benefits both the buyer and the supplier. We propose a method to select supplier for the SCM using multi-criteria decision analysis method.

First, it is important to identify the key supplier selection criteria, we find that price, delivery precision, quality, capacity and location are the important factors in supplier selection processes. The selection criteria are classified under the significant performance categories like delivery performance, quality performance etc. Then we use the solution methodology of the polychromatic sets to set up an evaluation model, the model plays a key role of evaluating and identifying competitive suppliers. This process reduces the sets of 'all' suppliers to a smaller sets of acceptable suppliers. Then, we use the genetic algorithm to select the better suppliers.

\section{SYSTEM MODEL}

\subsection{Supplier Evaluation Model}

There are five factors under the supplier performance level. Figure 1 shows the decision-making structure for evaluating supplier performance. The factors are selected based on the most common and significant issues in supply chain.

The main model is composed of two levels. First level is to find the elements that meet the evaluation factors. Second level, suppliers current situations are represented .Table 1 contains this two levels, and shows the relation among the polychromatic sets.

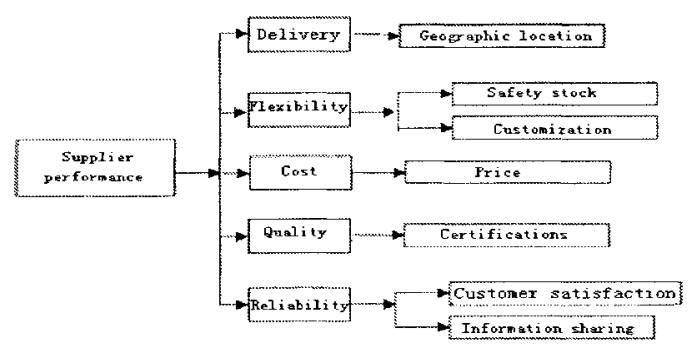

Figure 1. Supplier Performance Evaluation Structure 
Table 1. Relation among the Polychromatic Sets

\begin{tabular}{|c|c|c|c|c|c|c|c|}
\hline & $\begin{array}{l}\text { Guang } \\
\text { dong }\end{array}$ & EDI & ISO & $\begin{array}{l}\text { After } \\
\text {-sales } \\
\text { service }\end{array}$ & $\begin{array}{l}\text { Indepe } \\
\text { ndent } \\
\text { technol } \\
\text { ogy }\end{array}$ & $\begin{array}{l}\text { Mass } \\
\text { producti } \\
\text { on }\end{array}$ \\
\hline Delivery & $\begin{array}{l}\text { Geographic } \\
\text { location }\end{array}$ & 0 & & & & & \\
\hline \multirow[t]{2}{*}{ Flexibility } & Safety stock & & & & & & - \\
\hline & Customization & & 0 & & & - & \\
\hline Cost & Price & & & & & & - \\
\hline Quality & Certification & & & e & & & \\
\hline \multirow[t]{2}{*}{ Reliability } & $\begin{array}{l}\text { Customer } \\
\text { satisfaction }\end{array}$ & & & & 0 & & \\
\hline & $\begin{array}{l}\text { Information } \\
\text { sharing }\end{array}$ & & - & & & & \\
\hline \multirow[t]{3}{*}{ Supplier } & A & & - & & 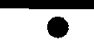 & 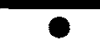 & \\
\hline & B & - & & & 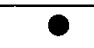 & & \\
\hline & $\mathrm{C}$ & 0 & - & & & - & \\
\hline
\end{tabular}

For the sake of simplicity, the relation matrix of elements, as shown in table 2.

Table 2. Supplier Performance Relation Matrix

$$
\left(\begin{array}{llllll}
1 & 0 & 0 & 0 & 0 & 0 \\
0 & 0 & 0 & 0 & 0 & 1 \\
0 & 1 & 0 & 0 & 1 & 0 \\
0 & 0 & 0 & 0 & 0 & 1 \\
0 & 0 & 1 & 0 & 0 & 0 \\
0 & 0 & 0 & 1 & 0 & 0 \\
0 & 1 & 0 & 0 & 0 & 0 \\
0 & 1 & 0 & 1 & 1 & 0 \\
1 & 0 & 0 & 1 & 0 & 0 \\
1 & 1 & 0 & 0 & 1 & 0
\end{array}\right)
$$

\subsection{Choose Process}

The following descriptions depict the buyer's situation and needs. The buyer, located in Guangdong province, China, is currently under market pressure to reduce costs and is looking for a supplier that can satisfy buyer's demand changes. However, the buyer wants to make sure that the selected supplier has fast and reliable methods that can serve its just-in-time system. For this reason, suppliers must obtain a long- 
term and stable partnership with effective communication channels. So it is important that the suppliers have a good EDI system and business online system that can improve the normal flow of goods and the decision-changing process at different points in the supply chain.

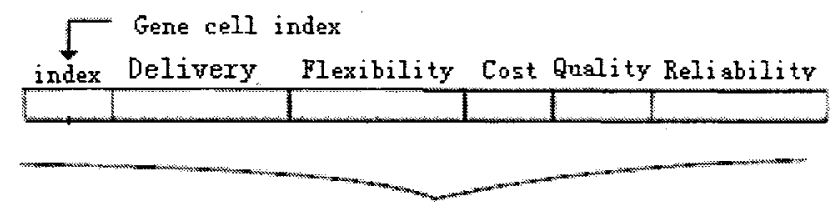

Chromosome

Figure 2. Structure of the Chromosome

From the model based on the polychromatic sets, we can see only the supplier A and supplier $\mathrm{C}$ meet the demand of buyer. Following the procedure, we use genetic algorithm to select the better supplier.

Encoding of chromosomes is the first question when starting to solve a problem with GA. Figure 2 shows the structure of the chromosome used for this case study.

Other parameters related to genetic algorithm are listed as follows:

- The maximum number of GA generations is set as 500 .

- The probability of crossover operation is set as 0.9 .

- Mutation is performed immediately after the crossover with probability 0.01 .

The following equation shows the supplier evaluation model:

Total supplier score $=$ delivery score + flexibility score + quality score + reliability score - cost score

This equation is generated to evaluate the fitness of each individual; the result is shown as follows.

Table 3. The Result of GA

\begin{tabular}{|l|l|}
\hline & GA to stochastic chance-constrained programming \\
\hline Supplier A & 0.87 \\
\hline Supplier B & 0 \\
\hline Supplier C & 0.13 \\
\hline
\end{tabular}

For the allocation of problem in stochastic chance-constrained programming, the results obtained are $0 \%$ from Supplier B, $87 \%$ from supplier A, and $13 \%$ from supplier C . 


\section{CONCLUSIONS}

The actual supplier selection problems always meet lots of uncertain factors and challenges in a complex changeable circumstance. This paper proposes an integrated assessing model for buyers to solve the supplier selection problem. This model is focused on finding the fundamental supplier combination that will best maximize the total score, Genetic algorithm has been designed for the problem. The experiments demonstrate the genetic algorithm and the models could promise ways for business area. Further research should add more factors that affect supply chain performance, such as how political influences affect supply chain operations and supplier performance, and how suppliers reacting to satisfy customer delivery deadlines. Adding these issues to the weighting scheme in the decision matrix will enhance the application of this supplier evaluation and selection model and improve SCM process.

\section{ACKNOWLEDGEMENTS}

The research in this paper is supported by the scheming item of science and technology by Guangdong province (2004B50101004, 2005B50101011)

\section{REFERENCES}

1. L.D. Boer, L. Eva, and M. Pierangela, A review of methods supporting supplier selection, European Journal of Purchasing \& Supply Management. Volume 7, Number 2, pp.75-89, (2001).

2. G. Dicksen, An analysis of vendor selection systems and decisions, Journal of Purchasing. Volume 2, pp.5-17, (1966).

3. R. Dulmin and V. Minimno, Supplier selection using a multi-criteria decision aid method, Journal of Purchasing \& Supply Management. pp.177-187, (2003).

4. C.A. Weber, J.R. Current, and W.C. Benton, Vendor selection criteria and methods, European Journal of Operational Research. Vol ume 50, pp.2-18, (1991).

5. Z. Li and L. Xu, Polychromatic sets and its application in simulating complex objects and systems, Computers and operations research. Volume 30, Number 6, pp.851-860, (2003).

6. L. Xu, Z. Li, S. Li, and F. Tang, A polychromatic sets approach to the conceptual design of machine tools, International Joumal of Production Research. Volume 43, Number 12, pp.2397-2421, (2005). 